\title{
FRONTERAS DEL NORMATIVISMO: A EJEMPLO DE LAS FUNCIONES DE LA INFORMACIÓN EN LOS PROGRAMAS DE CRIMINAL COMPLIANCE*
}

\author{
NORMATIVISM BORDERS: A SAMPLE OF THE FUNCTIONS OF INFORMATION IN CRIMINAL
}

COMPLIANCE PROGRAMS

Eduardo Saad-Diniz ${ }^{* *}$

\begin{abstract}
Resumo:
Neste artigo, são expostas as fronteiras do normativismo penal frente às estruturas normativas da sociedade econômica, observando como as novas funções da informação e a institucionalização dos programas de criminal compliance nos permitem compreender movimentos de expansão e integração supranacional por meio das normas penais.
\end{abstract}

Palavras-chave: Normativismo. Criminal compliance. Expansão do Direito Penal.

\begin{abstract}
:
The aim of this paper is to depict the criminal normativism frontiers, facing the normative structures of the economic society and observing how the new information functions and institutionalization of criminal compliance programs allow us to comprehend the expansion's movement and supranational integration concerning to criminal norms.
\end{abstract}

Keywords: Normativism. Criminal compliance. Criminal Law's expansion.

Quando ainda um "menino" na Faculdade de Direito, a vida me presenteou com a oportunidade de ser estagiário do Antonio Augusto. Revendo minhas memórias, encontrei o Ofício com que há quase dez anos (19.02.04) me dirigi ao Senhor Diretor e pedi o desligamento das atividades de estágio: "Encerro neste ofício todas as ricas e fecundas experiências que se me afiguraram e a imensa honra de haver participado ativamente da elaboração dos fascículos de nossa Revista e do Relatório Anual de Atividades, somados pela Assessoria de Imprensa. Ao ensejo, saliento a necessidade de incentivo e investimento neste importante Setor, carente de respaldo e reconhecimento de nossa Faculdade para melhor desempenho de suas atividades. Não fosse o espírito e a nobreza acadêmica do Senhor Antonio Augusto Machado de Campos Neto, a quem rendo minhas sinceras homenagens, muito mais pela ternura e humildade no trato do que pelas refinadas qualidades intelectuais, e de quem esta Faculdade é tributária dos

\footnotetext{
Trabajo originalmente presentado en el seminario "Constitucionalización en la sociedad mundial", en la Universidad Diego Portales, en Santiago del Chile (25-26.10.2013). Las citas en otros idiomas fueran libremente traducidas.

** Profesor Doctor del Departamento de Derecho Público de la Facultad de Derecho de Ribeirão Preto de la USP.
} 
merecidos louros; foi um verdadeiro anjo protetor por entre as experiências mais plurais que um homem pode em sua vida experimentar. Fica meu agradecimento a este servidor exemplar, de mãos dadas com a saudade e com os melhores sentimentos marcados por uma forte lembrança”. Já feito professor em Ribeirão Preto, dedico-lhe estes estudos com os mesmos sentimentos. Muito obrigado, Augusto!

\section{Introducción}

Las fronteras del normativismo en derecho penal se inmiscuyen en las comunicaciones sobre la estructura normativa de la sociedad, ${ }^{1}$ donde el delito y la pena van adquiriendo sentido en la misma medida en que son señalados, práctica y cotidianamente, los ámbitos de libertad de las personas y su consecuente responsabilidad. "El concepto funcional de norma, como expectativa estable y contra-fáctica de comportamiento, presupone la toma de decisión sobre la obediencia o no de la norma, si ella llena adecuadamente o no su función regulativa. De allí se deducen las demás características esenciales de la norma, como la derivación procedimental de legitimidad o la composición de elementos de grandeza moral, además es claro, de las expectativas de sanción y todas las consecuencias (simbólicas) que pueden ser derivadas, sea para la estabilización del incierto, sea para dimensionar el futuro". ${ }^{2}$ Cuando se ponen en cuestión los comportamientos económicos, no solamente la economía puede observar las formas de alocación eficiente frente a las normas penales, sino que también el derecho penal manifiesta capacidad de regular el comportamiento de los agentes económicos, y, por lo tanto, el funcionamiento del mercado, así como formula un sistema de imputación de responsabilidad a las libertades económicas. Observar las fronteras del normativismo significa entonces comprender los vínculos posibles entre las normas penales y el funcionamiento del mercado. ${ }^{3}$

En una realidad mundial en la que las ventajas de la eficiencia alocativa pone en jaque la capacidad de regulación estatal del funcionamiento del mercado, las nuevas funciones de la información inducen al desarrollo del sistema penal de protección de la comunicación e imposición de deberes de colaboración con el Estado. El debate de las nuevas funciones de la información se da en función de un contexto mundial,

\footnotetext{
JAKOBS, Günther. System der strafrechtlichen Zurechnung. Frankfurt: Vittorio Klostermann, 2012. p. 14. SAAD-DINIZ, Eduardo. Inimigo e pessoa no direito penal. São Paulo: LiberArs, 2012. p. 54 y ss.

"Tipos completos de negocios y ramos de la economía pueden solamente florecer porque la jurisprudencia penal estima que todavía es legal un comportamiento económico que no es totalmente serio, tal como ilustra el ejemplo del sistema comercial de donaciones: éste seguramente no podría existir en la misma magnitud que actualmente tiene si el Tribunal Federal alemán hubiera reconocido un deber de informar sobre el monto que se destina a los gastos, monto que frecuentemente es exorbitante", TIEDEMANN, Klaus. Derecho penal y nuevas formas de criminalidad. Trad. Manuel Abanto. Lima: Grijley, 2009. p. 187-188.
} 
desde la trasplantación de international legal standards de responsabilidad penal y gobernanza global que exigen la flexibilización de ordenamientos jurídicos, estimulando la integración supranacional por las vías también de normas penales. Integración, tal cual lo concibió Niklas Luhmann, se entiende por el proceso de "limitación recíproca de grados de libertad de los sistemas". ${ }^{4}$ En el ámbito penal, sin embargo, ese proceso choca con sus límites de legitimación. ${ }^{5}$ Para demostrarlo, haremos una observación de los movimientos de expansión de las normas penales y sus posibles aportes en la verificación de los international legal standards, para después discutir cómo las nuevas funciones de las informaciones impusieron dudosas prácticas de simetrización en el derecho penal, buscando eficacia en la regulación de los regímenes de transparencia de información, además de la institucionalización de nuevos mecanismos para prevención de la criminalidad fundamentados en deberes de colaboración con el Estado. Finalmente, a título de colofón, seguirán algunos de los reflejos más relevantes de esas discusiones en las organizaciones y en la prestación de servicios jurídicos.

2. Movimientos de expansión de las normas penales

Disfrutando de amplio reconocimiento entre los penalistas, Jesús-María Silva Sánchez elaboró, aún en los años '90, un concepto analítico de elevada capacidad explicativa con respecto a la posibilidad de identificar movimientos de expansión del derecho penal y los desarrollos de la política criminal en las sociedades post-industriales. Su trazo más distintivo, como no podría ser de otra manera, está centrado en los reflejos de la globalización económica y de la integración supranacional en la dogmática jurídicopenal. Esa integración no necesariamente traería mejores niveles de auto-comprensión dogmática, poniendo en riesgo la política criminal garantista y flexibilizando las formas tradicionales de imputación de responsabilidad. ${ }^{6}$ De forma analítica, ese movimiento de expansión de las normas penales conducido por la globalización económica se permite verificar bajo algunas características esenciales: (1) orientación a la eficacia práctica de las medidas de prevención a la criminalidad económica, derivadas de exigencias políticas para la lucha contra la criminalidad transnacional; (2) la puesta en peligro de los intereses jurídicos esenciales tiene naturaleza efectivamente lucrativa, trayendo como consecuencia

$4 \quad$ LUHMANN, Niklas. Organización y decisión. Trad. Darío Rodríguez. México: Herder, 2010. p. 127.

5 "Un ordenamiento existente de la libertad no es un ordenamiento normativo abstracto, y se caracteriza porque sus integrantes comunican una libertad real y concreta puesta en el mundo. La libertad de los individuos presupone una condición de libertad", PAWLIK, Michael. Teoría de la ciencia del derecho penal. Trad. Eduardo Saad-Diniz y Cecilia Marcela Ugartemendía. Cuadernos de Política Criminal, n. 106/2012, p. 22.

$6 \quad$ SILVA SANCHEZ, Jesús-María. A expansão do direito penal: aspectos da política criminal nas sociedades pós-industriais. Trad. Luiz Otavio de Oliveira Rocha. 3. ed. São Paulo: Revista dos Tribunais, 2013. p. 97. 
delitos económicos cuya regulación jurídica es todavía insuficiente y dogmáticamente poco desarrollada; (3) la insuficiencia dogmática a veces se refleja en tendencias netamente punitivistas, o, en palabras de Silva, "si a eso se adiciona el evidente déficit de aplicación (Vollzugsdefizit) de la legislación penal en dichos ámbitos, dada la magnitud de la tarea asumida, parece razonable pensar que la menor certainty de la consecuencia jurídico-penal (o, en otras palabras, el inevitable carácter selectivo de la represión) se vea compensada con una mayor severity de la misma (esto es, con un refuerzo de los aspectos simbólicos de la sanción)"; y, por fin, (4) la naturaleza transnacional propia de la "integración", que hace que la influencia de la common law sea incontornable. ${ }^{7}$

Entonces, la expansión de las normas penales pertenece a un movimiento de integración político-criminal de las leyes penales desde arriba, produciendo normas penales u orientaciones marcadas por una política criminal de control de contingencias económicas. No obstante, esas tesis alineadas a una orientación político-criminal sufren de una cierta infra-complejidad. Su relativización teórica, forzada por el pragmatismo económico y la pérdida de consistencia del referencial sistémico, ${ }^{8}$ condenan las normas penales a niveles intolerables de indeterminación y falta de identificación precisa de lo que sea la interpretación político-criminalmente orientada. ¿Que sería esa política criminal? ¿La propia política considerada en cuanto sistema diferenciado? ¿Una política pública, que conjuga referencial axiológico y programa político de seguridad? ¿O aún una política jurídica, en el sentido más kelseniano de la acepción, que implementa ${ }^{9}$ la interpretación del derecho?

Aunque Klaus Tiedemann piense que la integración sería importante para la unificación en la dogmática de matriz alemana, que ejercería el rol de restricción de la punibilidad, ${ }^{10}$ en ese ámbito, Silva trae relevantes aportaciones críticas. Principalmente, la política criminal está limitada al ámbito de lo "disponible", justificando la necesidad de criterios materiales de control racional para justificar la imposición de pena frente a una violación normativa: de las alternativas posibles de interpretación, ¿esa es de facto la menos lesiva? ¿el interés protegido se superpone al interés lesionado? Lo que

SILVA SÁNCHEZ, Jesús-María. A expansão... op. cit., p. 98-100.

8 La representación sistémica del discurso jurídico-penal tradicional estaría inmersa en "terminologías de fachada", cuyo rendimiento sería insuficiente para la organización racional y construcción científica del sistema del derecho penal, PAWLIK, Michael. "Strafrechtswissenschaftstheorie. In: PAWLIK, Michael; ZACZYK, Rainer (Hrg.). Festschrift für Günther Jakobs, 2007, p. 473-474.

9 ROXIN, Claus. "Die Strafrechtswissenschaft vor den Aufgaben der Zukunft". In: ESER, Albin et al (Org.). Die deutsche Strafrechtswissenschaft vor der Jahrtausendwende, 2000, p. 387 y ss.

10 TIEDEMANN, Klaus. "Der Allgemeine Teil des Strafrechts im Lichte der europäischen Rechtsvergleichung. In: Festschrift für Lenckner, München, 1998, p. 433-434. No parece, sin embargo, que la conclusión de Silva sea tan disonante: "lo más probable será la adopción de tratados de uniformización, también en temas de Parte General, acompañados de esfuerzos para garantizar de hecho una aplicación la más homogénea posible de los mismos", SILVA SÁNCHEZ, Jesús-María. A expansão... op. cit., p. 108. 
propone Silva, en verdad, puede avanzar un tanto más allá de las tendencias políticocriminales, y eso específicamente a partir del necesario interrogante sobre la capacidad de integración eficiente de garantías en las normas penales. "Partiendo de una visión estricta del significado de la eficiencia económica, entiendo", dice Silva, "que no cabe justificar metodológicamente que ésta sea el único fin o el fin superior de la política jurídica". ${ }^{11}$ La interpretación de las normas penales no se reduce a abstracciones de naturaleza política, y encuentra en la persona sus límites ontológicos y en los derechos fundamentales sus límites normativos, entendidos como frontera infranqueable de las consideraciones de eficiencia, "dónde se encuentra el límite normativo-valorativo de las consideraciones de eficiencia y cómo (desde qué premisas) puede construirse" la interpretación de las normas penales.

La falta de consistencia sistémica de las soluciones de política criminal "justas y adecuadas a casos concretos" promovería, en verdad, contextos jurídicos de inestabilidad normativa. O, como así criticado por Ralf Dreier, el comportamiento decisorio apenas acumularía soluciones justas, que, sin embargo, serían meramente parciales en relación al sistema (Teilsystemgerechtigkeit). ${ }^{12}$ En términos sistémicos, la cuestión se explica de la siguiente forma: la perspectiva político-criminal no logra promover una apertura cognitiva que dinamice el cierre operacional del sistema; en vez de eso, lo deja vulnerable a aperturas a la política de la sociedad. "Las dificultades combinatorias de las estructuras normativas y de la comunicación de la represividad afectan la diferenciación funcional (en relación al ambiente) y el perfeccionamiento del sistema jurídico-penal, pervirtiendo sus finalidades y su potencia de intervención punitiva frente a la 'corrupción' de los códigos que diferencian la reacción penal". ${ }^{13}$ En esa delicada relación del derecho penal con la política, los movimientos de expansión de las normas penales traerían el riesgo de una ilimitada desdiferenciación, en nombre de "intereses directos del Estado" en la dinámica interna del sistema jurídico-penal. ${ }^{14}$ "Peor que eso es la producción de discurso jurídico-penal que deja vulnerable la auto-comprensión del derecho penal, rehén de sus propios principios y de la estructura política y social del País". ${ }^{15}$

Por otra parte, si las normas penales se alejan de la influencia políticocriminal y se alinean más al normativismo, lo injusto (Unrecht) asumiría la primacía de la interpretación y el concepto de persona informaría el sentido del sistema jurídico-penal, incluso como proyección al futuro: “(...) la categoría de un injusto independiente de la

11 SILVA SÁNCHEZ, Jesús-Maria. Política criminal y persona. Buenos Aires: Ad Hoc, 2000. p. 33 y ss.

12 DREIER, Ralf. Zu Luhmanns systemtheoretischer Neuformulierung des Gerechtigkeitsproblems. In: Rechtstheorie, 5, 1974, p. 189 e ss.

13 Con referencia a Marcelo Neves, SAAD-DINIZ, Eduardo. Inimigo e pessoa... op. cit., p. 91.

14 TAVARES, Juarez. Teoria do crime culposo. 3. ed. Rio de Janeiro: Lumen Juris, 2009. p. 187.

15 SAAD-DINIZ, Eduardo. Inimigo e pessoa... op. cit., p. 92. 
culpabilidad tiene su relevancia en primer término allí donde no se trata de la consecuencia jurídica 'pena' - es decir, del castigo de un hecho ya cometido -, sino donde se está ante la cuestión de si frente a un autor que se dispone a poner en peligro bienes jurídicos ajenos, se deben tomar medidas de defensa, es decir, donde la meta del acto coactivo de que se trata es de naturaleza preventiva". ${ }^{16}$

Tomando por base esa nueva diferenciación del injusto penal, se crean los medios dogmáticos suficientes para encargarse de padrones igualmente diferenciados de seguridad cognitiva, especialmente anticipando, preventivamente, reacciones predelictivas y perfeccionamientos de las normas de conducta. Haciendo hincapié en esos presupuestos teóricos, se puede operar la necesaria revisión de los presupuestos de legitimación constitucional de regulación penal de los comportamientos económicos, a fin de superar "los déficits democráticos de las instituciones surgidas en los procesos de integración" "17 supranacional en los movimientos de expansión de las normas penales. Así también las combinaciones posibles entre los códigos punible/no-punible (desarrollados originalmente desde una orientación sistémica por Hans Theile) ${ }^{18}$ ganan mayor capacidad de rendimiento (Leistungsfähigkeit) y legitimación democrática en la sociedad económica al perfeccionar los padrones de planeamiento funcional y gestión de riesgos.

\subsection{Expansión extensiva e intensiva}

Para la observación de la expansión de las normas penales se hace oportuna la crítica a las percepciones de coyuntura de esos movimientos penales, especialmente en el ámbito económico, reduciendo el fenómeno normativo a facciones meramente adaptativas del derecho penal, como si todo el movimiento se pudiera sintetizar en la adecuación a la sociedad económica. Se trata, sin embargo, de algo un tanto más complejo. David Felipe I Saborit, discípulo de Silva, escindió la expansión en un movimiento de doble rostro: (a) la expansión extensiva y (b) la intensiva. “(...) La denominada (a) expansión extensiva del Derecho penal, que se manifiesta singularmente en el campo socioeconómico: derecho de consumidores y trabajadores, inmigración ilegal, medio ambiente, mercados financieros, blanqueo, urbanismo, nuevas tecnologías, nuevas formas de corrupción política, etc. Este Derecho penal expansivo precisa de una ampliación de las formas de atribución de responsabilidad: irrupción masiva de bienes jurídicos supra-individuales, recurso a delitos

\footnotetext{
16 PAWLIK, Michael. ¿El paso más importante de la dogmática de la última generación? Reflexiones para la diferenciación entre injusto y culpabilidad en derecho penal. In: PAWLIK, Michael. La libertad institucionalizada, 2010. p. 129.

17 Como así señalado por SILVA-SÁNCHEZ, Jesús-María. A expansão... op. cit., p. 106-107.

18 THEILE, Hans. Wirtschaftskriminalität und Strafverfahren. Tübingen: Mohr Siebeck, 2009.
} 
de peligro abstracto, flexibilización de las reglas de imputación (autoría, dolo, comisión por omisión, anticipación de la fase ejecutiva), etc.". ${ }^{19}$

Por su parte, la (b) expansión intensiva “(...) se manifiesta en campos más tradicionales, singularmente en materia de terrorismo y crimen organizado, delitos sexuales, delincuencia grave violenta y delincuencia leve habitual. Se trataría pues de una expansión intensiva caracterizada, entre otros aspectos, por realzar el perfil del autor frente a la gravedad del hecho concreto, un severo incremento de penas, endurecimiento de la ejecución penitenciaria, ampliación de la supervisión no carcelaria, reformas procesales buscando rapidez y eficacia, etc." ${ }^{20}$

Tanto en la expansión extensiva como en la intensiva, lo que se pone en cuestión es la recomposición de las esferas individuales de organización de los individuos. Desde la perspectiva normativista, se puede identificar, a partir de Silva, que esos movimientos de expansión, tanto extensiva cuanto intensiva, impulsan la transferencia y asunción de funciones de protección de esferas ajenas. "En derecho penal eso implica la tendencia a la exasperación de los delitos de comisión por omisión". ${ }^{21} \mathrm{Y}$ es precisamente en esos ámbitos que se reconocen nuevas funciones de la información y su rol en la génesis de los deberes jurídicos de comunicación: son transferidas a terceros las funciones de preservación de la propia esfera jurídica (dimensión subjetiva de la sensación de inseguridad vs. la existencia objetiva de peligro - ejemplificar con las funciones de la información en la democracia), generando consecuencias, casi siempre gravosas, de progresiva restricción de las esferas de libertad de actuación arriesgada (Riskante Freiheiten). Esas restricciones se vehiculan por medio de injerencias, fundamentadas en los deberes de colaboración e información, ${ }^{22}$ ni siempre fáciles de encontrar legitimación en materia penal.

\subsection{International legal standards}

Los ciclos de expansión de las normas penales no se mueven así sin más. Hay toda una inteligencia de alineamiento a las normativas internacionales. Para evaluar esos ciclos de expansión en el ámbito corporativo, Klaus Tiedemann sugiere la observación a partir de una "cultura de la responsabilidad penal empresarial" (Kultur der Unternehmensstrafbarkeit). Esa percepción se insiere en el contexto más amplio de las transformaciones advenidas de la sociedad económica mundial, en que la

\footnotetext{
19 FELIP I SABORIT, David. “Observaciones a la expansión diez años después”. In: ROBLES PLANAS, Ricardo et al (Org.). La crisis del derecho penal contemporáneo. Barcelona: Atelier, 2010. p. 64-65.

20 FELIPE I SABORIT, David. Observaciones... op. cit., p. 64-65.

21 SILVA SÁNCHEZ, Jesús-María. A expansão... op. cit., p. 56.

22 SILVA SÁNCHEZ, Jesús-María. A expansão... op. cit., p. 56.
} 
expansión de las normas penales en ámbito económico se reproduce en los espacios de desreglamentación de los mercados e inestabilidades económicas típicas de situaciones de desintegración financiera del sistema económico. ${ }^{23}$ Las débacles sistémicas imponen sistemas diferenciados de seguridad de información netamente dedicados a operaciones de captación de recursos, protección patrimonial y preservación de la reputación de la empresa en ámbito internacional. Esos sistemas de seguridad incentivan el comportamiento del tipo comply or disclosure, formulación de códigos de conducta (estructuras de incentivos al comportamiento empresarial) y modelos de imputación diferenciados en vista del "déficit de organización" 24 o de los estados de "irresponsabilidad organizada" por la ausencia de normas que imputen responsabilidad a las empresas. Con la finalidad de garantizar la estabilidad del sistema económico, se recurren a prestaciones del sistema jurídico que instituyen deberes de colaboración específicos para la conducción de los comportamientos económicos.

Para recuperar la estabilidad de la gestión económica, Eduardo Opazo y Darío Rodríguez señalan que "se trata ni más ni menos que de una estrategia corporativa que debe incorporar un acabado diagnóstico de los escenarios que la empresa enfrenta en su medio social, los grupos prioritarios que la pueden afectar y los cuales afecta. El objetivo será desarrollar su actividad con altos grados de adhesión de sus públicos principales". ${ }^{25}$ Desde la sociología de las organizaciones, los deberes de colaboración adquieren también esa dinámica estratégica, evidenciando su capacidad de aprendizaje organizacional $^{26}$ frente a la necesidad de mantener una reputación corporativa y agregar valor frente a decisiones inciertas. "La comunicación del miedo y la desconfianza en las instituciones producen un ambiente de sospecha difícil de apaciguar". ${ }^{27}$

23 "Junto a la globalización, la corrupción y la criminalidad económica también experimentaron su auge. La crisis financiera reanimó la seducción de buscar los beneficios de la competencia por medio de caminos ilegales. Las leyes anticorrupción se recrudecieron y una rigurosa interpretación jurisprudencial reforzó la presión bajo la conducción de empresas en el sentido de la preocupación con un gerenciamiento adecuado de riesgo, a fin de garantizar el cumplimiento de las leyes. Al mismo tiempo, las empresas son cada vez más confrontadas por las reivindicaciones de compliance impuestas por los agentes de mercado" Wolfgang Schaupensteiner, "Rechtstreue im Unternehmen - Compliance und Krisenmanagement. Konzertiertes Vorgehen statt einzelbetriebliche Maßnahmen”. Disponível: http://www.schaupensteiner. de/_doc/20100617_Passau.pdf. Acesso: 04 abr. 2012 (trad. libre).

24 TIEDEMANN, Klaus. "Zur Kultur der Unternehmensstrafbarkeit”. In: QUELOS, Nicolas (Org.). Droit penal et diversités culturelles - Festschrift für José Hurtado Pozo, Basel: Schulthess, 2012, p. 495-512. Cfr. en detalles sobre el déficit de organización, NIETO MARTÍN, Adán. La responsabilidad penal de la persona jurídicas: un modelo legislativo. Madrid, 2008. p. 38 y ss.

25 OPAZO, Eduardo; RODRÍGUEZ, Darío. "Gobierno corporativo y los stakeholders". In: ENRIONE C., Alfredo. Directorio y Gobierno Corporativo. Santiago: Valiente, 2012. p. 104.

26 RODRÍGUEZ MANSILlA, Darío. Organizaciones para la modernización. In: México: Uni. Iberoamericana, 2004. p. 22 y ss.

27 OPAZO, Eduardo; RODRÍGUEZ, Darío. Gobierno corporativo... op. cit., p. 104. 
La mayor preocupación en la formulación de eso deberes en el ámbito corporativo está circunscrita a las principales conductas delictivas que afectan a la economía, como blanqueo de capitales, fraudes financieros, corrupción, organizaciones criminales e información privilegiada. Cuando son pensadas desde la perspectiva penal, “dan la impresión de espacios de impunidad que dejan a la sociedad vulnerable frente al poder de las corporaciones, intensificando las apelaciones morales por una intervención contra la malversación de la ética en la conducción de los negocios, sobre todo en comportamientos económicos que se valen de intereses públicos para generar beneficios privados", ${ }^{28}$ generando indeseables daños sociales (Sozialschädlichkeit).

Frente a la incertidumbre económica y desconfianza en la movilidad internacional de inversiones de capital, se tratan de crear international legal standards para incriminar determinados comportamientos económicos arriesgados. Se deducen de eso recombinaciones estructurales y también institucionales en las normas penales a nivel transnacional que ejercen una función de integración (Integrationsfunktion) ${ }^{29}$ de los mercados en el mismo nivel. La armonización de los marcos normativos penales no desatiende a las necesidades sistémicas de regular los contextos que ponen en peligro la identidad del mercado mundial. Lo que puede llevar a creer que la diferenciación de las expectativas económicas acabó provocando una diferenciación también en el ámbito del derecho penal económico, que se puede observar a partir de dos parámetros distintos: (1) un minimum standard de criminalización, en el que la injerencia penal se contiene en sus límites regulatorios y no ultrapasa el ideal de ultima ratio y de la subsidiariedad, pudiendo moverse, expandiéndose, hacía (2) un maximum standard de criminalización y mayor creencia en el potencial regulatorio de las normas penales. Dicho esquemáticamente, los ciclos de expansión se hacen observar y verificar empíricamente a partir de los padrones de incriminación de comportamiento económico informados en ámbito internacional y asimilado, en mayor o menor medida, en ámbito normativo nacional:

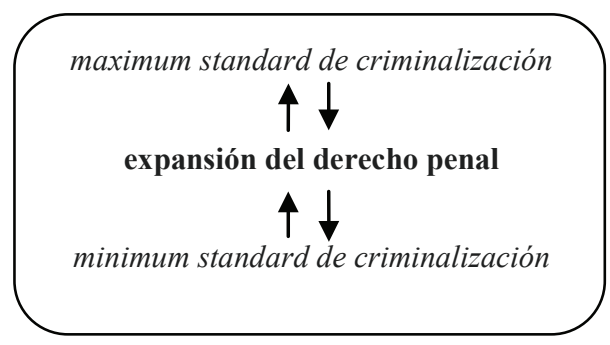

\footnotetext{
28 SAAD-DINIZ, Eduardo. O sentido normativo dos programas de compliance na APn 470/MG. Revista dos Tribunais, n. 933, p. 152 y ss.

29 TIEDEMANN, Klaus. Zur Kultur... op. cit., p. 495 e ss.
} 
La misma verificación de la expansión sí puede demostrarse en la hipótesis de la cultura de la responsabilidad penal empresarial de Tiedemann. Desde el minimum standard del societas delinquere non potest, que no reconoce la atribución de la responsabilidad penal de la persona jurídica, la expansión alcanza su máximo nivel en la responsabilización autónoma de las organizaciones empresariales, en el societas delinquere potest a la indiferencia de la responsabilidad de sus dirigentes. En el ámbito corporativo, los international legal standards se deciden en el campo de las decisiones de política económica que negocian parcelas de soberanía interna para adopción - o legal transplants ${ }^{30}$ - de padrones internacionales de gestión empresarial. Suficientemente significativa es la observación del caso chileno, en el que esas rodadas internacionales de negociación se hacen evidentes al promulgar la muy bien acabada ley de responsabilidad penal empresarial autónoma (Ley 20.393/2009) en el mismo contexto en que Chile accede a la condición de miembro efectivo de la Organización de Cooperación de los Países en Desarrollo (OCDE). ${ }^{31}$ El international legal maximum standard, por medio del cual Chile adoptó la responsabilidad autónoma de las organizaciones empresariales, mostró sus primeros signos en la protección penal ambiental en Brasil, a partir de la interpretación jurisprudencial en la Suprema Corte brasileña (RE 548.181/PR, 06.08.2013, Relatora Ministra Rosa Weber), dispensando las formas de concurso necesario de doble imputación de personas, de modo tal que la coautoría de los dirigentes de la empresa ya no se hace mas obligatoria. ${ }^{32}$

Esos ciclos de expansión y las trasplantaciones de padrones internacionales de comportamiento, más allá de estimular investigaciones empíricas para precisar la mayor o menor incidencia de international legal standards en la formulación e interpretación de normas penales, ponen en evidencia otras fronteras de normativismo: qué es la determinación moral de los conflictos socioeconómicos y su capacidad de reversión en negocios. El peligro es reducir la intimidación penal a la dimensión de las shame sanctions, las sanciones humillantes, que manejan la reputación y tienen especial valor en el ámbito corporativo. ${ }^{33}$

$30 \quad$ Más sobre en TIEDEMANN, Klaus. Zur Kultur... op. cit., p. 497.

31 Fabián Caparrós observa la supervisión por parte de la OCDE a la que se sometió Chile en el proceso de verificación de la adecuación de sus normas internas, a fines de ingresar como miembro efectivo de la OCDE, FABIÁN CAPARRÓS, Eduardo. "La reforma del cohecho transnacional a la luz del derecho comparado en el marco convencional de la cooperación y el desarrollo económico (el caso chileno)". In: ORSI, Omar G.; GARCIA, Nicolás R. (org.) Transparencia, acceso a la información y tratamiento penal de la corrupción. Buenos Aires: Del Puerto, 2011. p. 196 y ss., 203 y ss.

32 Sobre el concurso de personas en el modelo brasileño, SHECAIRA, Sérgio Salomão. Responsabilidade penal da pessoa jurídica. 3. ed. Rio de Janeiro: Elsevier, 2011. p. 166 y ss.

33 JÜNGEL, Marc. Shame sanctions: Wiedergeburt der Schandstrafe? Generalpräventive Plubizität und materieller Strafbegriff. Düsseldorf: Banana-wiss., 2011; para un análisis crítico, KUBICIEL, Michael. "Shame Sanctions: Ehrenstrafren im Lichte der Straftheorie". In: Zeitschrift für die Gesamte 


\section{Las funciones de la información}

\subsection{Transparencia y simetría}

Las ideas de gobernanza corporativa se encargan de poner la transparencia como epicentro del mercado. La comunicación en las organizaciones no está ceñida a la eficiencia financiera. Así concebida, la información incorpora nuevas y estratégicas funciones de (1) gestión organizacional (documentación, administración de conflictos y monitoreo de accionistas), (2) dinámica de colaboración para agregar valor, confianza y perfectibilización de la información, (3) manipulación de situaciones arriesgadas, de desintegración e inestabilidad típicas de crisis, (4) capacidad inclusiva (con la participación previa de los interesados en el proceso decisorio), (5) viabilidad de los sistemas de delegación de responsabilidad de y (6) certificación de la efectiva implementación de los modelos de seguridad.

En el mercado de capitales brasileño, esas funciones de la información obtuvieron sus instigaciones más significativas en el "Nuevo Mercado" y en la gobernanza regulatoria, que fueran adoptados sobre todo en las últimas décadas haciendo hincapié en las ideas filosóficas de Norberto Bobbio. Las principales modificaciones estructurales se alcanzaron a partir de iniciativas que impulsaron nuevas directrices éticas de conducta corporativa, políticas de seguridad institucional para garantizar la liquidez y valoración de las acciones y especialización del sistema de informaciones, en la misma línea de las trust based policies ('políticas basadas en la confianza'). En una entrevista, uno de los protagonistas del "nuevo mercado brasileño", llegó afirmar: "nosotros hicimos una transformación de una Bolsa elitista para una Bolsa popular, usando y aplicando algunos de los conceptos filosóficos de Norberto Bobbio. Él enseña que democracia es visibilidad, transparencia y acceso. Fue eso lo que aplicamos en Bovespa (Bolsa de Valores de São Paulo). Creamos el cargo de ombudsman, desarrollamos trabajos en conjunto con las fuerzas sindicales, creamos ese Nuevo Mercado. Tenemos esos proyectos visando a la responsabilidad social. También hicimos trabajos en conjunto para divulgar los conceptos de la Bolsa y del mundo del mercado mobiliario junto al Judiciario. Tenemos proyectos de educación financiera. Realizamos un trabajo "muito bonito"". ${ }^{34}$ La performance del nuevo mercado en Brasil fue incluso reconocida en el debate chileno: "el principal factor que explica lo que está ocurriendo en Brasil es el 'Novo mercado'. Lanzado a principios

Strafrechtswissenschaft, n. 118, 2006, p. 44-75; PAWLIK, Michael. Seht, dieses Schwein! In: FAZ, 16.11.2004.

34 In: Revista Getúlio, mai/jun.2008, p. 25. Cfr. en detalles, MAGLIANO, Raymundo. "Mercado de capitais, poder económico e regulação". In: FERRAZ JR., Tercio Sampaio et al (Org.). Poder econômico: direito, pobreza, violência, corrupção. Barueri: Manole, 2009. p. 11 y ss. 
del 2000 por Bovespa en San Paulo, este nuevo sistema está reservado para las compañías que voluntariamente se comprometen a mayores estándares corporativos que los legales dentro du propio gobierno corporativo".

En la economía de la sociedad, las configuraciones ideales de mercado recomiendan simetría de informaciones, con paridad equitativa del nivel comunicativo entre las partes interesadas. No por otra razón es que, en la gestión de la organización, "cautelar los derechos de posesión y uso de la información" 35 se convierte en el punto en que se concentran la libertad de conducción y la responsabilidad de los dirigentes, determinándoles sus deberes fiduciarios: deber de diligencia y cuidado (duty of care); deber de lealtad (duty of loyalty); deber de sinceridad (duty of candor), ${ }^{36}$ además del deber de documentación.

Además de eso, se busca garantizar la simetría desde la obligación de publicidad de la información, de tal forma que se les permita a los inversores el dominio necesario de la evaluación del riesgo inherente a su decisión. En ese sentido, la estandarización de los padrones de comportamiento, como p. ej. en el Global Reporting Initiative - GRI o el International Financial Reporting Standards - IFRS, es la salida viable que no solamente garantiza voluntariamente el espacio público del mercado, sino que, además, genera confianza. La confianza, a su vez, genera valor agregado de forma sostenible. ${ }^{37}$ De ahí la centralidad de los "regímenes de información" (Informationsregime): significa que no se imponen padrones de comportamiento a los stakeholders o a las organizaciones, sino que no se les garantiza determinados niveles de información. ${ }^{38}$ Desde el estudio de Christine Windbichler, hay aquí una doble función que protege a los inversores y también a las organizaciones, ya que la simetría "refuerza la base informacional de la decisión y condiciona la auto-protección del mercado". Sin embargo, la perspectiva normativizada de protección de la comunicación entre inversores y organizaciones, cede espacio para parámetros de regulación material de sectores o conductas concretas. Algunos regímenes ganan especificidad en la misma medida en

35 PEZOA, Álvaro. La responsabilidad ética del director de empresas. In: ENRIONE C., Alfredo. Directorio y gobierno corporativo. Santiago: Valiente, 2012. p. 97.

36 CONCHA, Germán. La regulación vigente en Chile en relación a la responsabilidad de los directores de sociedades anónimas". In: PEZOA, Álvaro. "La responsabilidad ética del director de empresas. In: ENRIONE C., Alfredo. Directorio y gobierno corporativo. Santiago: Valiente, 2012. p. 79-80.

37 "La obligación de proporcionar al público información respecto de la situación de la sociedad anónima parte de la premisa que la información en poder de la compañía es propiedad privada, que tiene valor económico pues le ha costado a la sociedad anónima producirla, custodiarla e incluso mejorarla". BOZA, Beatriz. La responsabilidad del directorio en materia de información. In: PEZOA, Álvaro. La responsabilidad ética del director de empresas. In: ENRIONE C., Alfredo. Directorio y gobierno corporativo. Santiago: Valiente, 2012. p. 122.

38 WINDBICHLER, Christine. Kapitalmärkte als Vorsorgeinstrument. In: MÜNKLER, Herfried et al. (Org.). Handeln unter Risiko. Bielefeld: transcript, 2010. p. 204. 
que se especializa el comportamiento decisorio en la economía, demandando nuevos artificios regulatorios que inciden sobre determinados contenidos y perfeccionan la corporate disclosure, así como fue el caso estadunidense con el Sarbanes Oxley-Act de 2002, seguidos de las sentencing guidelines, con el objetivo de controlar las asimetrías de información y evitar comportamientos dañosos e ineficientes movidos por la oportunidad de lucro. ${ }^{39}$

Bajo esas nuevas cualidades, la información adquiere también una función crítica, que le permite captar un sentido operativo más adecuado a la compleja dinámica del mercado mundial, especialmente en el reconocimiento de las fallas estructurales de la regulación o de las alternativas jurídico-penales que son propuestas. ¿No sería demasiado ingenuo creer que el recurso a las normas penales bastaría para sanear la cultura financiera, mejorando los standards de gobernanza? ¿Tendría el derecho penal complejidad suficiente para manejar las informaciones e identificar los problemas de diagnóstico organizacional (déficit de organización), apuntando límites normativos de capital regulatorio o tipificando un parámetro mínimo de capitalización y control del flujo de pagamentos, responsables por el exceso de liquidez? O aún más delicado: ¿sobre qué tipo de información y bajo qué procedimientos debe incidir el deber de informar?

Si bien es verdad que "los inversionistas desean trasparencia, información de calidad y protección de sus intereses", ${ }^{40}$ a la función esencial de la información, que es garantizar la trasparencia y reforzar la confianza de los negocios, se agrega además otra relevante dimensión de la colaboración: el desafío estratégico de la integración latinoamericana. Gonzalo Larraguibel ya se había adelantado sobre la cuestión: "esta situación regional, quizás única en historia, abre infinitas oportunidades de negocios y creación de valor a las empresas pero, al mismo tiempo, obliga a que sean repensados los modelos de negocio, de decisión, de gestión de la organización y del talento que se han utilizado hasta ahora y que sean aceptados a las nuevas necesidades de negocios, incrementalmente complejos, internacionales, de mayor tamaño y riesgo" ${ }^{41}$ Por eso es

39 WINDBICHLER, Christine. Kapitalmärkte... op. cit., p. 205.

40 "Evidentemente, los inversionistas institucionales desean incrementar el valor de los patrimonios administrados. Dicho valor depende, por un lado, del potencial de las empresas de generar flujos crecientes en el tiempo, pero también de riesgos asociados. Desean y exigen entonces altos estándares en cuanto a desempeño, transparencia, integridad de estados financieros, resolución apropiada de conflictos de interés y, en general, todas las condiciones propias de un buen gobierno corporativo". ENRIONE, Alfredo. Gobierno Corporativo: un imperativo de hoy. In: PEZOA, Álvaro. La responsabilidad ética del director de empresas. In: ENRIONE C., Alfredo. Directorio y Gobierno Corporativo. Santiago: Valiente, 2012. p. 28-29.

41 Que están insertos en tres agendas estratégicas típicas: (1) capturar oportunidades de crecimiento, orgánico e inorgánico, local y muchas veces internacional; (2) mejorar la eficiencia e impacto de los modelos actuales de negocio; (3) responder a nuevas necesidades de liderazgo de las organizaciones, LARRAGUIBEL, Gonzalo. "El directorio y la estrategia, de la reflexión a la acción". PEZOA, Álvaro. La responsabilidad ética del director de empresas. In: ENRIONE C., Alfredo. Directorio y Gobierno Corporativo. Santiago: 
que, para asegurar la simetría entre los stakeholders, las formas jurídicas se especializaron, a fines de establecer las expectativas que los agentes económicos deben cumplir para mantener el nivel de colaboración necesario para el funcionamiento eficiente de los mercados e implementar modelos legítimos de cooperación económica regional.

Esos deberes se produjeron a partir de combinaciones normativas $\mathrm{y}$ mecanismos sancionatorios implementados en las instituciones, ${ }^{42}$ trayendo al ámbito criminal los programas de compliance, cuyos conceptos se extraen de las mismas orientación de gobernanza: risk management, value management, corporate governance, business ethic, integrity codes, codes of conduct y corporate social responsibility, ${ }^{43}$ en adelante discutidos.

\subsection{Recurso a las normas penales como refuerzo punitivo}

El problema surge cuando esta información lleva a que los stakeholders comuniquen sus decisiones económicas con base en informaciones no confiables, sin acceso al mínimo relevante para identificar la formación de los precios y orientar la toma de decisión. Para viabilizar la dinámica de la comunicación corporativa, el mercado recurre al refuerzo penal para hacer cumplir la política de gestión de las organizaciones empresariales reguladas por la gobernanza. La tendencia expansionista apela a la intimidación penal como mecanismo de monitoreo de la toma de decisión en ámbito corporativo (corporate internal decisión structure), incentivando el cumplimiento de los nuevos padrones de colaboración.

La verdad es que la simetría de informaciones y la transparencia no pueden ser una ilusión semántica con tan poca funcionalidad. "El secreto es el alma de los negocios" es el dicho popular en Brasil. El secreto, y no la confianza. El secreto permite engañar, emplear los métodos corporativos de la forma más hábil y mañosa para lograr el lucro. Negar información y engañar puede de facto generar más valor que la confianza. Incumben a las formas jurídicas entonces nuevas diferenciaciones para, por un lado, desincentivar el engaño, y, por otro, incentivar la generalización de la confianza. La mayor preocupación es que, fracasando la generalización de expectativas de transparencia en las informaciones, el mercado busca hacer triunfar la eficacia de sus normas mediante el refuerzo punitivo de la intimidación penal, hasta un punto tal que, exigiendo la simetrización de las informaciones en el comportamiento económico, se proponga

Valiente, 2012, p. 142.

42 En detalles, ENGELHART, Marc. Sanktionierung von Unternehmen und Compliance. 2. ed. Berlin: Duncker \& Humblot, 2012. p. 563 y ss.; EICKER, Andreas. Die Prozeduralisierung des Strafrechts. Bern: Nomos, 2010. p. 168 y ss.

43 SIEBER, Ulrich. op. cit., p. 451 e ss. 
encontrar legitimación en su trato con la protección asimétrica de la información en del derecho penal.

Con elevada acuidad analítica, Vogel contrapuso las funciones de la información en el derecho de mercado de capitales, simétricas, y en el derecho penal, asimétricas. Vogel demuestra, sobre todo, la extensión del deber de simetría de informaciones trasladado de un ámbito a otro, que produce una ampliación considerable de la injerencia en las esferas individuales, en contraposición a los dictámenes de legalidad, presunción de inocencia, o derecho de no producir prueba contra sí mismo, ${ }^{44}$ en una forma netamente asimétrica entre individuos y Estado. Vogel también analiza que, si bien la evitación de delitos empresariales puede representar un equivalente funcional que interese a la subsidiariedad del derecho penal ("la evitación del conflicto torna la pena superficial"), la prevención de delitos que no aporte en la distribución de los ámbitos de libertad y responsabilidad de los individuos es "ilegítima y disfuncional". ${ }^{45}$ El Estado se aleja de la imposición de la pena, en una dudosa marcha hacia la privatización del monopolio de la intervención punitiva.

Asimismo, Wolfgang Frisch desarrolla una concepción normativa de la información, tomando por base la normativización del engaño fundada en el derecho a la veracidad de las informaciones y en defraudaciones de expectativas de las víctimas. ${ }^{46}$ Michael Pawlik también lo hace, pero desde un "entendimiento restrictivo del engaño que toma fuertemente en cuenta la autorresponsabilidad de los destinatarios" en la "adquisición de información", distribuyendo el "riesgo de orientación" "entre el autor de un comportamiento potencialmente engañoso y su destinatario". ${ }^{47}$ Esas perspectivas no significan que en las fronteras del normativismo se sitúa necesariamente una expansión de las normas penales con vista al recrudecimiento de las incriminaciones. Por el contrario, crea un sistema penal de protección de la comunicación y de las función de veracidad (autenticidad, información insospechada y exacta), que disminuye la incidencia de injerencia penal en la exacta medida en que perfecciona su calidad normativa, dejando claramente evidentes los criterios entre la libertad de acción económica y los límites de la tolerancia del Estado a la actividad económica lícita y exitosa.

44 VOGEL, Joachim. "Estafa en la UE". Trad. Adán Nieto Martin. In: ARROYO ZAPATERO, Luis et al (Org.). Fraude y corrupción en el derecho penal económico europeo. Cuenca, 2006. p. 48.

45 VOGEL, Joachim. Wertpapierhandelsstrafrecht... op. cit., p. 732-733.

46 FRISCH, Wolfgang. Cuestiones fundamentales del engaño y el error en la estafa. Revista de Derecho Penal y Procesal Penal. n. 5, 2011, p. 785 y ss.

47 PAWLIK, Michael. ¿Engaño fraudulento por medio del envío de cartas de oferta similares a una facturación? Revista de Derecho Penal y Procesal Penal. n. 5, 2011, p. 809. 
De la misma manera, en cuanto al refuerzo punitivo, sucede la misma expansión normativa en relación a la "cultura de la anti-corrupción" ${ }^{48}$ y los acuerdos de cooperación de los sistemas internacionales anti-blanqueo. En esos ámbitos, sucede que los propósitos de integración en regla son distorsionados por determinadas preferencias particularistas, más propias de la competencia económica, que pueden reducir las dimensiones de la cooperación a mero conflicto supranacional. Sin hablar del riesgo moral $\mathrm{y}$ de los costos sociales inherentes a las decisiones económicas, ${ }^{49}$ es necesario someter las informaciones a una verificación de proporcionalidad, no apenas en relación a la intensidad de los vínculos estructurales entre las organizaciones y el mercado, sino también relativamente a su nivel de organización, al grado de dependencia económica coyuntural de determinados sectores de la actividad corporativa y la evaluación de impactos de las crisis económica, si es el caso de nuevas formas de integración regional en Latinoamérica.

Los análisis del comportamiento económico complejo y la utilización de las informaciones son más que legítimos. Lo inapropiado, en verdad, son los casos en que estas informaciones, si fuera el caso de trading privado, no son llevadas al conocimiento del mercado de capitales, abriendo la oportunidad para casos de información privilegiada (insider trading). Brasil ya siente las primeras repercusiones prácticas de esa discusión, y conoció su primera condena de insider trading en febrero de 2013, fundamentada en la violación del deber de lealtad y secreto de informaciones $\mathrm{y}$, con un fuerte carácter normativista, reconoció la "confianza depositada en los inversores del mercado, a fin de asegurar el correcto funcionamiento del mercado de capitales". ${ }^{50}$

48 La noción de recurso a normas penales como medidas de refuerzo punitivo ya había sido criticada por Abanto: "después de períodos de amplia corrupción política, no se discute abiertamente sobre las causas mismas del problema, sino se tienden a repetir los mismos errores, creyendo que bastarían las medidas penales. Además, las mismas estructuras que favorecieron el incremento incontrolado de la corrupción permanecen inalteradas (incluso los mismos agentes corruptores se apropian del discurso de la 'lucha contra la corrupción')". ABANTO VÁSQUEZ, Manuel. La lucha contra la corrupción en un mundo globalizado. In: LOSANO, Mario; MUNOZ CONDE, Francisco. El derecho ante la globalización y el terrorismo. Valencia: Humboldt, 2004. p. 278.

49 En el modelo luhmanniano, la moral no puede constituir un sistema social funcionalmente diferenciado. Puede pertenecer a un comportamiento decisorio del derecho, o de la política, o de la economía, o de la ciencia, por ejemplo, sin que llegue a caracterizar un código binario que indique su observación, cfr. LUHMANN, Niklas. Die Moral der Gesellschaft. Frankfurt: Suhrkamp, 2008. p. 56.

50 "Además, la credibilidad de las operaciones del mercado de valores mobiliarios se consubstancia en la transparencia de informaciones y en la divulgación amplia de hecho o acto relevante a fines de garantizar la igualdad de condiciones a todos los inversores de operar en el mercado de capitales", AP 2009.61.81.0051234/SP, Relator Desembargador Luiz Stefanini, 14.02.2013. Según Vega, en lugar de violación del deber institucional de lealtad frente al mercado, se trata en verdad de "delito especial de dominio", con necesaria verificación de la determinación positiva del hecho, utilización de la información con independencia de si vulnera un deber extrapenal existente y si incinde de forma apreciable sobre la cotización de los valores e instrumentos negociados, VEGA GUTIÉRREZ, José Zamyr. Mercado de valores y derecho penal. Montevideo: B de f, 2013. p. 225 y 236. 
Las funciones asimétricas del derecho penal no son mera casualidad. La restricción de libertad económica por medio de la publicidad de informaciones relevantes para decisiones de los inversores no resiste a la misma paradoja que la responsabilidad penal empresarial. Lo que en principio sería la evidencia "en último análisis, la ambigüedad de funciones de las normas penales, oscilando entre protección de la sociedad contra el poder de las organizaciones y la creación de una identidad de mercado, remonta al debate más amplio entre la garantía de la seguridad de las relaciones de negocio vs. la restricción de las libertades de actuación en el mercado. El dilema mayor consiste en el hecho de que restringir la libertad económica de determinadas empresas acaba por ampliar la seguridad de los negocios, de forma tal que una restricción de libertad puede generar, también paradójicamente, ampliación de libertad a las demás empresas". ${ }^{51}$

\subsection{Activismo regulatorio}

Como supra planteado, desde las funciones de la información, las formas jurídicas se diferenciaron para buscar mayor eficacia en la persecución penal (law enforcement). Con distintos matices, en Brasil se observa una verdadera profusión de normas con la finalidad de regular la libertad económica, generando un estado de auténtico "activismo regulatorio", que puede sentirse en dos distintos niveles: (a) administrativo y (b) legislativo penal-económico. ${ }^{52}$

$\mathrm{A}$ (a) nivel administrativo, el alineamiento a los international legal standards, sobre todo a partir de los padrones de Basilea III, se produce en la intensificación y especialización de los programas de seguridad de informaciones en el ámbito empresarial. De 2004 a 2009, por ejemplo, se observa que el Banco Central del Brasil (BACEN) saltó, en sus recomendaciones, de la previsión de 43 operaciones sospechosas para 106, bajo la idea de perfeccionar la capacidad de los bancos de reaccionar ante la inestabilidad económica y ampliar el potencial de prevención de peligros, especialmente en lo que concierne a la financiación de terrorismo.

Más allá de ampliar los costos de transacción en el ámbito corporativo, trayendo nuevas variables económicas que dañan especialmente a las organizaciones empresariales de pequeño y medio porte, la regulación administrativa de deberes con consecuencias penales reporta al problema de la técnica de la norma penal en blanco en los delitos económicos. En otra ocasión, pude analizar la cuestión de los vacíos de

${ }_{51}$ SAAD-DINIZ, Eduardo... op. cit., p. 157-158.

52 En otras ocasiones, se buscó demostrar el activismo también en el ámbito de la política judicial en Brasil, SAAD-DINIZ, Eduardo. Nova lei de lavagem de dinheiro no Brasil: compreendendo os programas de criminal compliance. Revista Digital IAB, n. 8/ 2013, p. 104 y ss. 
descripción normativa en relación a los comportamientos económicos que se deben "llenar" con descripciones advenidas de otros sistemas jurídicos: "Pero no es cualquier norma que puede llenar un blanco, esa creatividad para solucionar los problemas económicos encuentra obviamente sus límites. Las normas son decurrentes de actos administrativos elaborados en un ambiente institucional especializado para intermediar las transacciones en las instituciones financieras o comunicar las operaciones sospechosas de blanqueo de capitales. Con esa técnica, el derecho penal busca perfeccionar las normas penales, recibiendo informaciones de otros ramos del derecho para ofrecer una respuesta regulatoria en relación al funcionamiento del mercado. Al menos en tesis es así que se propone a una mayor eficacia. Técnicamente, el sistema sancionatorio no está inmune a los problemas de descripción de comportamiento con que tanto sufren las normas penales, ya que los actos administrativos también pueden comunicar un contenido impreciso o insuficiente". 53

Por su parte, en el (b) nivel legislativo penal-económico: (b.1) la nueva Ley de Blanqueo (12.683/2012), los programas de compliance advienen de las políticas de incentivo a la adopción de sistemas de inteligencia e información sobre operaciones sospechosas de blanqueo de capitales. Los principales mecanismos con respecto a eso son: 1) art. 10, III y IV, adopción de políticas de prevención, 2) deberes de comunicación del art. 11, II y III, 3) delimitación de la responsabilidad del empresario dirigente e 4) indicación del compliance officer; (b.2) la nueva Ley de competencia - (cuya capacidad de planeamiento del Estado generó aportes financieros de gran monta, en razón de que los agentes económicos se anticiparon a las infracciones puestas por el Consejo Administrativo de Defensa Económica, “apurando una ola de adquisiciones de R\$10 mil millones de reales" ${ }^{54}$ ); (b.3) la nueva Ley anticorrupción, aunque limitada a los ámbitos privados y administrativos, recomienda una serie de consecuencias penales; (b.4) la nueva Ley de organizaciones criminales.

En los últimos informes del Grupo de Acción Financiera - GAFI, que regula el blanqueo de capitales en nivel supranacional, el "activismo" brasileño mereció muchos elogios, apuntando apenas la ausencia de legislación que tipifique de forma autónoma las asociaciones terroristas.

\section{Los programas de criminal compliance}

Las fronteras del normativismo penal se ponen en relieve cuando se cotejan sus estructuras tradicionales y la inestabilidad del mercado. El comportamiento decisorio

53 SAAD-DINIZ, Eduardo. A técnica da norma penal em branco. Valor Econômico, 19.10.2012.

54 In: Valor Econômico, 30.05.2012. 
en economía se diferencia por la idea de oportunidad de lucro, que adviene de juicio de cálculo de probabilidades sobre el potencial y la disponibilidad de recursos en niveles más elevados de productividad. Por eso es que el problema del derecho penal económico ya no resiste con sus postulados clásicos de legalidad e individualización de la culpabilidad, sino, por el contrario, con la descripción bien acabada del comportamiento complejo de los agentes económicos y el nuevo régimen de necesidad de intervención penal en el ámbito de las organizaciones empresariales. O sea, las normas penales que se proponen a regular el funcionamiento de los mercados toman nuevas estructuras normativas en la sociedad económica, en particular estimulando la adopción de programas de criminal compliance.

Joachim Vogel definió la compliance como "concepto que proviene de la economía y que fue introducido en el derecho empresarial, significando la posición, observancia y cumplimiento de normas, no necesariamente de naturaleza jurídica. Para garantizarse la compliance, no se puede prescindir de la buena conducción de la empresa (corporate governance) (... y determinación de la) compliance organisation". ${ }^{5}$ De hecho, la "complementariedad funcional" 56 de las normas penales acopladas a otros ámbitos del derecho y de la economía incrementa la racionalidad del derecho penal económico, pensándose que de ahí se originan nuevas posibilidades de combinación entre la conducción de la actividad empresarial y la prevención de la criminalidad económica. ${ }^{57}$ Ulrich Sieber, por su parte, discrimina al menos seis etapas para la consolidación de un programa de compliance en el ámbito penal económico: (1) comunicación de finalidades y valores de la organización relativamente a la procedimentalización y gestión de riesgos; (2) determinación de las esferas de responsabilidad de los dirigentes y de la sección de compliance; (3) sistema de informaciones y disclosure (Hinweisgebersystem); (4) mecanismos de control interno y externo; (5) medidas sancionatorias frente a los abusos; (6) estructuras de incentivo (Anreizstrukturen) para el cumplimiento del deber. ${ }^{58}$ Marc Engelhart sitúa los programas en el plan de la punibilidad de las empresas y hace una muy detallada investigación comparada entre los EUA y en Alemania. En cuanto a los EUA, discrimina los presupuestos teóricos de la responsabilidad de las personas jurídicas (a. que un empleado haya cometido un delito; b. que sea cometido en el ámbito de las relaciones

\footnotetext{
55 VOGEL, Joachim. Wertpapierhandelsstrafrecht. In: PAWLIK, Michael; ZACZYK, Rainer (Hrg.). Festschrift für Günther Jakobs, 2007, p. 407 y ss. En detalles sobre las variaciones del concepto de compliance, ENGELHART, Marc. Sanktionierung... op. cit., p. 40 y ss.

56 POLAINO-NAVARRETE, Miguel; POLAINO-ORTS, Miguel. Las insolvencias punibles en la encrucijada del derecho penal y del derecho mercantil: Tras la aprobación de la nueva Ley Concursal española. Bogotá: Universidad Externado de Colombia, 2005, p. 74 y ss.

57 THEILE, Hans. Unternehmensrichtlinien: Ein Beitrag zur Prävention von Wirtschaftskriminalität? Zeitschrift für Internationales Strafrechtsdogmatik, n. 09, 2008, p. 406 y ss.

58 SIEBER, Ulrich. Op. cit., p. 458 (trad. libre).
} 
de empresa; c. que se demuestre el dolo de accionar en beneficio de la propia empresa) y critica las aplicaciones del respondeat superior y de las due diligence defenses. En la experiencia alemana, lo que se discute con mayor énfasis son los efectos de los standards de conducta para la evitación de las infracciones de deber, de conductas omisivas, de autoría por fuerza del dominio de organización, ${ }^{59} \mathrm{y}$ en todos esos ámbitos de incidencia, las funciones de la información ejercen un rol decisivo.

Es, sin embargo, a partir de las sugerencias de Wolfgang Schaupensteiner que se llega a la síntesis, por un lado, en la caracterización del modelo básico de compliance, que comprende la adopción de una política de prevención a la criminalidad empresarial y la implementación de mecanismos de control interno y también externo, $\mathrm{y}$, por otro, sus formas específicas de implementación, a depender de la naturaleza del riesgo, de la adecuación de los mecanismos regulatorios, de las dimensiones de la empresa y de la complejidad del negocio, ${ }^{60}$ sin limitarse a las políticas de prevención al blanqueo de capitales, extendiéndose a otros dominios empresariales, como la compliance socioambiental, médica o incluso en el ámbito de las relaciones de trabajo.

Con relación a las normas penales, lo que realmente interesa es comprender sus vínculos posibles con la gestión de la organización empresarial conforme a la gobernanza, trayendo como consecuencia la asunción de padrones diferenciados de comportamiento para el cumplimiento de deber y atribución de responsabilidad, ${ }^{61}$ desde nuevas formas de colaboración y cooperación entre organizaciones y el propio Estado: la "auto-regulación regulada".

\subsection{Autoregulación reglada}

La nueva connotación de las informaciones en ámbito corporativo produce, por consiguiente, una novedosa forma de acoplamiento estructural entre sus mecanismos de organización interna y los vínculos de regulación a partir de nuevos deberes de colaboración externa. Es decir, las nuevas funciones de la información permiten una regulación de la libertad de organización interna de las empresas, vinculándolas a los mecanismos de control y verificación externos de esa organización. Dicho en términos sistémicos y aproximándose al modelo luhmanniano, Ulrich Sieber describe este fenómeno de la siguiente manera: “(...) formas de 'auto-regulación’ y 'co-regulación' (que) posibilitan, en un mundo complejo, nuevas formas de regulación en el ámbito de

\footnotetext{
59 ENGELHART, Marc. Sanktionierung... op. cit., p. 87 y ss. y 398 y ss.

60 SCHAUPENSTEINER, Wolfgang. Grundzüge innerbetrieblicher und konzertierter ComplianceManagement-Systeme, p. 11. Disponible en: <http://www.schaupensteiner.de/_doc/20101203_Deggendorf. pdf>. Acceso en: 04 abr. 2012.

${ }^{61}$ Em detalhes, SAAD-DINIZ, Eduardo. O sentido normativo... op. cit., p. 158 y ss.
} 
la economía. Eso se torna claro cuando los nuevos corporate codes son vistos, desde una observación teórico-sistémica, como constitución autónoma de la empresa y sistemas auto-reflexivos o autopoiéticos (es decir, que se auto-regulan). En esta consideración profundizándolo aún más - se realizan el potencial regulatorio autónomo y la validez jurídica autónoma de la constitución de la empresa de la que habla la sociología, que también se muestra como 'derecho sin Estado'. Esos sistemas de regulación no-Estatales se destacan especialmente por sus efectos globales". ${ }^{62}$ Es cierto que la "auto-regulación regulada" de la que habla Sieber determina una retirada del Estado y la institucionalización de los deberes de información proporciona la "cooperación funcional" entre el ámbito privado y el público. La información opera el acoplamiento estructural entre los dos ámbitos en la exacta medida en que se torna disponible por medio de una recomendación y el incentivo correlato. En líneas generales, los programas de compliance establecen el compromiso de conducir las informaciones, trasladándolas del ámbito corporativo a las instancias de control. Es así que Sieber logra superar los déficits de regulación del sistema privado, imponiendo, por la enforced self-regulation, esos deberes de comunicar las informaciones esenciales al funcionamiento del mercado, anticipándose a las formas de comunicación económica que manipulan la información de forma punible y demandan la imputación de responsabilidad penal. ${ }^{63}$

Basándome en tres momentos regulatorios, propuse distinguir la evolución de esas formas de la siguiente manera: 1) regulación privada; 2) regulación pública; 3) co-regulación público-privada. La auto-regulación del conflicto, ésta sí aislada de la presencia del Estado, se reporta al cumplimiento de las normas penales conforme a la percepción de lucro: si cometer un delito puede generar más lucros que la obediencia a las normas. La regulación con fuerte presencia del Estado incluye al propio Estado como una variable económica, si él puede o no ser concebido como factor de inducción del crecimiento económico. Y para regular la auto-regulación, ya en un tercer momento, lo más interesante sería encontrar los incentivos que combinan procedimientos empresariales de auto-regulación, con sus prestaciones de deberes de información, orientados por preceptos del Estado para su prudente fiscalización y cumplimiento de las recomendaciones de gobernanza. ${ }^{64}$ En cada una de esas etapas regulatorias, las informaciones no dejan de ocupar un rol central. Y, sin embargo, a partir de la psicología comportamental - que irá a analizar los aspectos subjetivos del comportamiento económico (antes de todo un comportamiento

\footnotetext{
${ }^{62}$ SIEBER, Ulrich. Compliance-Programme in Unternehmensstrafecht: Ein neues Konzept zur Kontrolle von Wirtschaftskriminalität. In: SIEBER, Ulrich et al (Org.). Strafrecht und Wirtschaftsstrafrecht Dogmatik, Rechtsvergleich, Rechtstatsachen- Festschrift für Klaus Tiedmann zum 70. Geburtstag. Berlin: Carl Heymanns Verlag, 2008. p. 458, 476 e ss. (trad. libre).

63 SIEBER, Ulrich. Compliance-Programme... op. cit., p. 476.

${ }^{64}$ En detalles, SAAD-DINIZ, Eduardo. O sentido normativo... op. cit., p. 152 y ss.
} 
humano), que pueden llevar a excesos de confianza o inseguridad cognitiva -, o, inclusive, de aplicación de las neurociencias en el ámbito corporativo en la discusión de la evolución de la auto-regulación regulada es posible identificar una interface muy significativa entre el análisis microeconómico del derecho penal y la teoría de los sistemas, especialmente en el dominio de las dimensiones de manipulación de la información (imperfecta, fragmentada, difusa en las complejas estructuraciones del derecho societario, o incluso falsificadas) en la determinación de los deberes de colaboración público-privados.

Lothar Kuhlen - aunque admitiendo que la teoría de los sistemas permite interpretar los programas de criminal compliance como "modus" de observación de la forma como la economía observa los vínculos entre el derecho penal y la economía misma, "irritándose recíprocamente" - critica expresamente dichas formulaciones abstractas. Lo hace dispensando la idea de acoplamientos estructurales de co-regulación. Lo que sería la auto-regulación regulada, según él, no necesita ser pensado bajo categorías sistémicas, ya que aleja la comprensión a los "no-iniciados" (Nicht-Inaugurierte) en sus tesis centrales. ${ }^{65}$ En todo caso, lo que importa es comprender cómo los particulares y las organizaciones pueden adherir a la cultura del disclosure y mecanismos sancionadores internos sin que se pierda la centralidad estatal en la prevención de la criminalidad económica, o, como ya lo criticaba en Brasil Juarez Tavares, sin que haya un "desmonte del Estado" en materia de seguridad. ${ }^{66}$

Günther Teubner también describe esos fenómenos a partir de una "llave de lectura" distinta en el ámbito transnacional, observando un movimiento global de "autoconstitucionalización" representada por los códigos corporativos. "La globalización posibilita el recurso al mercado financiero como 'arbitraje regulatorio"" ${ }^{67}$ Pero, con fundamento en la crítica luhmanniana de los costos de la auto-diferenciación promovida por los standards corporativos en la sociedad mundial, Teubner reconoce la doble reflexividad de los códigos de conducta corporativos, en que la capacidad operativa de las organizaciones crea modificaciones internas a partir de constricciones externas, impuestas por los límites a la libertad de actuación empresarial en el ámbito de los derechos humanos, socio-ambientales y laborales. ${ }^{68}$ La complejidad del comportamiento

${ }_{65}$ KUHLEN, Lothar. "Grundfragen von Compliance und Strafrecht”. In: KUHLEN, Lothar(Org.). Compliance und Strafrecht, C.F. Müller, 2013. p. 17.

${ }_{66}$ TAVARES, Juarez. A globalização e os problemas da segurança pública. In: HOLLENSTEINER, Stephan (org.) Estado e sociedade civil no processo de reformas no Brasil e na Alemanha. Rio de Janeiro: Lumen Juris, 2004. p. 64-65.

${ }_{67}$ WÜNSCH, Oliver. Paradox der Geldwäschereibekämpfung: Eine ökonomische Analyse. Zürich, 2008, p. 03.

68 TEUBNER, Günther. Autoconstitucionalização de corporações transnacionais? In: SCHWARTZ, Germano (Org.). Juridicização das esferas sociais e fragmentação do direito na sociedade contemporânea. Porto Alegre: Livraria do Advogado, 2012, p. 109 y ss. 
económico, sin embargo, aprende con esa doble reflexividad y no deja de legitimar nuevas formas de agregar valor aún cuando su comportamiento parece no ser orientado por el lucro, de tal forma que ostentar una policy making sostenible en términos de derechos humanos, paradójicamente, incorpora valor a la empresa, atrayendo a los inversores que actúan bajo las ideas de gobernanza, tornándose, igualmente, "factor de competencia" 69 en la sociedad mundial.

Ya observando la sociedad latinoamericana, la diferenciación funcional de los sistemas se compromete, según lo interpreta Marcelo Neves, generando corrupción sistémica (que es, además, cíclica, por la formación de estructura de expectativa de nuevas actividades corruptas), y depende de las organizaciones reestructurar el sistema. ${ }^{70}$ Por eso es que los programas de compliance en el ámbito criminal acaban no dejando de producir ciertos niveles de inestabilidad normativa. En ese ámbito de expansión normativa orientada por international legal standards, la asunción de padrones rígidos de cumplimiento de deberes, basados en organizaciones de la modernidad central, puede ampliar demasiado la expansión de la intervención penal en las organizaciones latinoamericanas. Así, según Darío Rodríguez: "el desconocimiento de esta estrecha vinculación entre sociedad y organización ha llevado a que en Latinoamérica se hayan importado constantemente modelos de organización, tratando de conseguir construir organizaciones más eficientes guiadas por la racionalidad formal propia de las sociedades occidentales, de donde los modelos provienen. Parecía sencillo intentar esa copia de un modelo probadamente eficiente - en su lugar de origen - porque no se entendía que un modelo es también un producto cultural, que no puede ser trasladado sin tomar en consideración las variables culturales que constituyen el modelo, ni tampoco las propias de la cultura en que este modelo deberá adaptarse". ${ }^{71}$ Que en Brasil tuviésemos el mismo padrón de comportamientos corporativos, y sus deberes de colaboración para la auto-regulación regulada, significaría también que concordamos con el mismo rigor de intimidación y represión a las infracciones. ${ }^{72}$

${ }_{69}$ Específicamente sobre compliance como "factor de competencia", WÜNSCH, Oliver. Paradox... op. cit., p. 71 y ss.

70 NEVES, Marcelo. Aumento de complexidade nas condições de insuficiente diferenciação funcional: o paradoxo do desenvolvimento social da América Latina. In: SCHWARTZ, Germano (Org.). Juridicização das esferas sociais e fragmentação do direito na sociedade contemporânea. Porto Alegre: Livraria do Advogado, 2012. p. 203.

71 RODRÍGUEZ, Darío. Diagnóstico organizacional. 7. ed. Santiago: Ediciones UC, p. 126 y ss.

72 Cfr. más sobre en SILVEIRA, Renato de Mello Jorge; SAAD-DINIZ, Eduardo. Criminal compliance: os limites da cooperação normativa quanto à lavagem de dinheiro. Revista de Direito Bancário e de Mercado de Capitais, n. 56, 2012, p. 308-309. 


\subsection{Límites de legitimación de la regulación penal}

La regulación de la auto-regulación ya tiene sus límites desde el momento de su instrumentalización dogmática. Desde este punto de vista, la gestión de riesgos en el ámbito corporativo encuentra criterios materiales de restricción. El propio Silva, por su parte, propone que se obedezca a un proceso descriptivo de las conductas dañosas, en el que sea posible determinar los indicios de no cumplimiento o que reclamen inspección, etapas necesarias para evitar la ilimitada generalización de deberes de colaboración de mera conducta peligrosa.

Por ahora, serán discutidos apenas algunos de los límites: respecto a (a) las finalidades de los programas de criminal compliance; (b) pérdida de movilidad del comportamiento económico y aumento de los costos de transacción; (c) protección de los empleados en los sistemas de delegación de deberes; (d) mecanismos de intensiva verificación de la aplicación de los derechos fundamentales. ${ }^{73}$

Según Thomas Rotsch (a) las finalidades de los programas de criminal compliance se destinan a la reducción del ámbito de incidencia de la punibilidad del comportamiento empresarial, ${ }^{74}$ lo que, sin embargo, tiene como consecuencia un comportamiento económico anterior que anticipa la punibilidad aún en el ámbito de la organización, en una verdadera auto-incriminación, atribuyendo relevancia penal a determinadas conductas, ${ }^{75}$ a indiferencia de un proceso penal y las garantías a él correspondientes. Giovanni Saavedra, en la misma línea de pensamiento, identificó allí una paradoja sociológica: incluso cuando la compliance tenga el propósito de disminuir la responsabilidad penal empresarial, ella acaba expandiendo las hipótesis de punibilidad de la empresa. ${ }^{76}$

Por otro lado, se observa (b) pérdida de movilidad del comportamiento económico y aumento de los costos de transacción, ya que la fijación de standards de comportamiento económico retira la flexibilidad exigida por la dinámica del mercado.

73 SILVA SÁNCHEZ, Jesús-María. Hacia el derecho penal de Estado de la prevención. In: SILVA SÁNCHEZ, Jesús-María. ¿Libertades ecónomicas of fraudes punibles? Madrid: Marcial Pons, 2003. p. 315 y 316.

74 ROTSCH, Thomas. Criminal Compliance. Zeitschrift für Internationales Strafrechtsdogmatik, n. 10, 2010, p. 615 .

75 ROTSCH, Thomas. Criminal compliance... op. cit., p. 615-616. Seguido por BOCK, Dennis. Stand der strafrechtswissenschaftlichen Compliance-Diskussion in Deutschland. In: ROTSCH, Thomas (Hrg.). Wissenschaftliche und praktische Aspekte der nationalen und internationalen Compliance-Diskussion. Baden-Baden: Nomos, 2012. p. 66.

76 SAAVEDRA, Giovani A. Criminal Compliance aus brasilianischer Sicht. In: ROTSCH, Thomas (Hrg.). Wissenschaftliche und praktische Aspekte der nationalen und internationalen Compliance-Diskussion. Baden-Baden: Nomos, 2012. p. 154. 
Dennis Bock analiza que los "costos burocráticos" generan el constreñimiento de las libertades de organización, llegando incluso a afectar su potencial de innovación. ${ }^{77}$

En lo que respecta a (c) los mecanismos de protección a los empleados en el ámbito corporativo, se tornan aún más delicados los retos de prevención por medio de los programas de compliance. ¿Bajo presión de los programas de compliance, pueden los dirigentes imponer la evitación de delitos sin violar la intimidad de sus empleados? O sea ¿cómo ponderar sobre la colisión de deberes existente entre los deberes de control de los empresarios y la protección de la privacidad de sus empleados? ${ }^{78}$ Esa oposición entre, por un lado, los deberes de informar y vigilar, y, por otro, los deberes personales, pone de vuelta en el tapete el concepto de persona, recomendando elaboración de criterios materiales de restricción de la imputación de responsabilidad en los sistemas de delegación de deberes corporativos.

Pero ninguno de esos interrogantes puede tener mayor importancia para la legitimación de los programas de compliance que (d) los mecanismos de intensiva verificación de la aplicación de los derechos fundamentales. En la línea de la constitucionalización del orden jurídico, institucionalizando deberes entre privados, entes de Estado o mismo que recomienden deberes de colaboración en la relación entre privados y entes de Estado, Matthias Jestaedt orienta el recurso "intensivo" a la verificación constitucional: "la Constitución no se reduce a mero derecho especial (Sonderrecht) de las relaciones políticas, sino que asciende a un orden de valores penetrante en cada una de las relaciones jurídicas". ${ }^{79}$ Esa verificación intensiva se constituye en un poderoso instrumento de limitación de los ámbitos de incidencia de los deberes, reduciendo los impactos observados en la institucionalización en los programas de compliance y las presiones por integración y cooperación en las libertades individuales.

4.3. A título de colofón: reflejos en las organizaciones y en la prestación de servicios jurídicos.

Esas son apenas las primeras observaciones sobre las fronteras del normativismo para la consolidación de un modelo racional de regulación penal de las expectativas económicas. En ocasión de análisis crítico de la Acción Penal n. 470, que juzgó el más rumoroso escándalo de corrupción de la historia reciente en Brasil, envolviendo a algunos de los miembros de Gobierno Lula da Silva, intenté hacer las primeras reflexiones

77 BOCK, Dennis. Stand... op. cit., p. 66.

78 Interesantes aportes en AGUSTINA SANLLEHÍ, José R. El delito en la empresa. Barcelona: Atelier, 2009. p. 231 y ss.

79 JESTAEDT, Matthias. Phänomen Bundesverfassungsgericht. Was das Gericht zu dem macht, was es ist. In: Das entgrenzte Gericht. Frankfurt: Suhrkamp, 2009. p. 86. 
sobre las repercusiones de la intimidación penal en la prestación de servicios jurídicos: ${ }^{80}$ desde mi punto de vista, se vehiculó "la idea de que esta intimidación serviría como reacción al poder económico de las organizaciones y a los escándalos de corrupción. No parece que sea así de simple. Lo que está en juego es una lógica de alineamiento internacional e integración de los mercados por medio de la regulación penal, transitando de la represión para la prevención. De ahora en adelante, lo que importa al penalista es comprender que debe encontrar espacios de actuación profesional en las estructuras previas (ex ante) de gobernanza, por medio de los programas de gestión empresarial. En lugar de la intimidación, creación de estructuras de incentivo al cumplimiento de los deberes de colaboración con el Estado en la prevención a la criminalidad económica. En vez de la rutina de las condenaciones criminales, comportamiento estratégico y gestión de riesgo por medio de procedimientos internos de cumplimiento de deber para protección de la organización empresarial, en que la interpretación de las leyes penales comunique también una descripción bien acabada del orden jurídico del mercado. En ese contexto surge la figura del nuevo defensor penal, inserido en cultura organizacional de diligencia y cuidado, lealtad y sinceridad en la prevención a la criminalidad económica". ${ }^{81}$

Con fundamento en la adecuación constitucional del modelo de seguridad pública vinculado a expectativas económicas, las habilidades profesionales del defensor criminal se desarrollan a partir de las posibilidades de interacción funcional con otros sistemas jurídicos y con lo que aprende en las organizaciones, especialmente en lo que respecta a sus nuevos roles, como gestor-negociador, que preserva su reputación frente a las instituciones y a las redes negociales, ostentando aptitud extra-procesal y conocimientos extra-jurídicos sólidos y crecientemente especializados, cada vez más tendientes al diálogo multi-profesional, superando el tradicional concepto personalista del defensor. "Más allá de lo permitido/prohibido en la solución del caso", continúo en mi análisis, "el defensor deberá 'gobernar' el conflicto, apuntando los problemas da anticipación de punibilidad en las diligencias, pudiendo sugerir alternativas a la regulación excesiva o asimétrica. De la misma forma, si es el caso de deberes demasiado ingenuos - como creer que habrá denuncias a las operaciones sospechosas en el ámbito interno de la empresa, o que los

80 Distintas formas de evaluación de la prestación de servicios jurídicos en CAMPILONGO, Celso. “Assessoria jurídica popular: falsa promessa?". SCHWARTZ, Germano (Org.). Juridicização das esferas sociais e fragmentação do direito na sociedade contemporânea. Porto Alegre: Livraria do Advogado, 2012. p. 231 y ss.

81 SAAD-DINIZ, Eduardo. O novo defensor... op. cit.

82 En detalles, SAAD-DINIZ, Eduardo. Notas sobre a intervenção da mídia no livre convencimento e o papel do 'novo defensor penal'. In: PEDRINA, Gustavo Mascarenhas de Lacerda. AP 470. São Paulo: LiberArs, 2013. p. 269 y ss. Cfr. JAHN, Matthias. Der Unternehmensanwalt als 'neuer Strafverteidigertyp' und die Compliance-Diskussion im deutschen Wirtschaftsstrafrecht (Teil I). Zeitschrift für Wirtschaftsstrafrecht und Haftung im Unternehmen. 12/2012, p. 477-520. 
clientes serían entregados a la fiscalización - o que pueden detener el funcionamiento eficiente de la empresa". Y concluí escindiendo dos ámbitos de observación: "desde el punto de vista microeconómico, consta de su formación profesional la habilidad de la adopción, implementación y certificación de esas estructuras de incentivo. En la perspectiva macro, la capacidad de anticipar la política económica, estableciendo los vínculos con la política criminal específica para la integración del mercado" ${ }^{83}$

En cierre, con esos argumentos intenté exponer las fronteras del normativismo penal frente a las estructuras normativas de la sociedad económica, observando cómo las nuevas funciones de la información y la institucionalización de los programas de criminal compliance nos permiten comprender movimientos de expansión y integración supranacional por medio de las normas penales.

São Paulo, enero de 2013.

SAAD-DINIZ, Eduardo. O novo defensor... op. cit. 